\title{
STUDI PERANCANGAN IDENTITAS VISUAL WILAYAH KARIMUNJAWA (bagian 1)
}

\author{
Arif Priyono Susilo Ahmad \\ Jurusan Desain Komunikasi Visual, Faculty of Humanities, BINUS University \\ Jln. KH. Syahdan No. 9, Palmerah, Jakarta Barat 11480 \\ arifpsa@binus.edu
}

\begin{abstract}
Effective communication is a critical need in our lives. Communication that is not running properly will impede the flow and the system of social activity. Living in a world filled with information needs language as a right marker so that the meaning of a message can be conveyed properly. At such moments, a marker, which also functions as the identity for the people, demands to look unique, creative, communicative, and comprehensible globally, beyond the boundaries of culture and geography. Visual markers of an area are needed so that miscommunication can be reduced. Visual markers were developed in regard to communication strategies within the context of destination branding. Sharp communication strategy would manifest in the form of creative concept, a kind of platform on which to base and the main idea behind the overall design visualization. Manifestation the visual form of logo design, typography, tone color, shapes, graphic elements, mascot, pictograms, wayfinding, posters, merchandise, and so on. The visual identity of the region, in relation to destination branding program, specifically intended for a destination region, will raise the values of locality, the uniqueness, diversity, and distinctiveness of the region. Designing visual identity Karimunjawa region in this case study apply the principles of creativity and uniqueness that is processed into a visual appealing, distinctive, and attractive, yet understated and powerful in raising local elements.
\end{abstract}

Keywords: visual semiotic, destination branding, visual identity, logo, pictogram

\begin{abstract}
ABSTRAK
Komunikasi yang efektif adalah kebutuhan yang penting dalam kehidupan kita. Komunikasi yang tidak berjalan dengan baik akan menghambat alur dan sistem dalam aktivitas sosial. Hidup di dunia yang penuh dengan informasi memerlukan bahasa sebagai penanda yang tepat agar makna sebuah pesan dapat tersampaikan dengan baik. Pada saat seperti itu, penanda yang sekaligus berfungsi sebagai identitas bagi masyarakat dituntut dapat tampil unik, kreatif, komunikatif dan dapat dipahami secara global, melewati batasbatas budaya dan geografi. Penanda visual sebuah wilayah diperlukan agar miskomunikasi dapat dikurangi. Penanda visual dikembangkan dengan memerhatikan strategi komunikasi dalam konteks destination branding. Strategi komunikasi yang tajam akan mewujud dalam bentuk konsep kreatif, yaitu semacam platform yang menjadi dasar dan gagasan utama yang melatarbelakangi visualisasi desain secara keseluruhan. Wujud visualnya berupa desain logo, desain tipografi, tone warna, bentuk, elemen grafis, maskot, piktogram, wayfinding, poster, merchandise, dan sebagainya. Identitas visual suatu wilayah, dalam kaitannya dengan program destination branding, yang khususnya ditujukan bagi suatu wilayah tujuan wisata, sebaiknya mengangkat nilai-nilai (value) lokalitas, keunikan, keragaman dan kekhasan dari wilayah tersebut. Perancangan identitas visual wilayah Karimunjawa dalam studi kasus ini menerapkan prinsip-prinsip kreativitas dan keunikan yang diolah menjadi visual yang menarik, khas, dan atraktif, namun tetap bersahaja dan kuat dalam mengangkat unsur-unsur lokal.
\end{abstract}

Kata kunci: semiotika visual, destination branding, identitas visual, logo, piktogram 


\section{PENDAHULUAN}

Perhatian awal kita tentang Indonesia adalah wilayah yang sangat luas yang kaya akan sumber daya alam dan menyimpan banyak potensi, namun pengelolaan wilayah dan asetnya belum menjadi tuntutan utama. Destination branding yang menjadi alat untuk mengomunikasikan tata kelola destinasi pun masih dipahami sebagai kosmetik semata. Saat ini diperlukan pendidikan dan inisiatif mengemas destinasi menjadi tumbuh dan dinamis melalui program yang tepat dan dikomunikasikan dengan kreatif. Branding wilayah atau destination branding adalah salah satu cara penandaan suatu wilayah baik secara tangible maupun intangible yang dikembangkan sebagai sebuah identitas yang berkarakter khas dan kuat sebagai salah satu pendorong kegiatan pariwisata di suatu wilayah. Dalam strategi destination branding, terdapat tujuh elemen penting sebagai prasyarat terciptanya destinasi yang baik, yaitu pariwisata, people, governance, export, investment/immigration, culture \& heritage. Sebuah konsep destination branding, didasari oleh passion dan identitas yang menarik yang saling berhubungan dengan berbagai hal yang akan memudahkan orang memiliki asosiasi dengan tempat tersebut. Destination branding diyakini memiliki kekuatan untuk merubah persepsi dan merubah cara pandang seseorang terhadap suatu tempat atau tujuan, termasuk melihat perbedaan sebuah tempat dengan tempat lainnya untuk dipilih sebagai tujuan. Program branding yang dilambangkan dengan logo atau simbol adalah memvisualkan gagasan dan cita-cita menjadi sebuah ikon yang mampu mengimajinasikan atau menggambarkan cita-cita tersebut. Simbol atau icon ini akan berfungsi sebagai awareness campaign yang memiliki asosiasi positif, imajinatif dan mudah dipahami. Artikel ini mengulas studi kasus perancangan identitas visual wilayah Karimunjawa yang dasar pemikirannya adalah implementasi dari konsep destination branding. Pada bagian awal akan dijabarkan situasi mengenai Karimunjawa, pengembangan strategi kreatif dan proses perancangan desain hingga implementasi desain.

\section{Tentang Taman Nasional Karimunjawa}

Kepulauan Karimunjawa secara administratif merupakan kecamatan dari wilayah kabupaten Jepara, yang berlokasi sekitar 45 mil arah barat laut kota Jepara. Luas wilayah teritorial Karimunjawa adalah 107.225 ha, sebagian besar berupa lautan (100.105 ha), luas daratannya sendiri adalah 7.120 ha.Daerah ini beriklim tropis yang dipengaruhi oleh angin laut yang bertiup sepanjang hari dengan suhu rata-rata 26 s.d. 30 derajat Celcius, dengan suhu minimum 22 derajat Celcius dan suhu maksimum 34 derajat Celcius. Keindahan panorama alam seperti terumbu karang, rumput laut, dan padang lamun dengan biota laut yang beraneka ragam, hutan mangrove, gunung dan sisa hutan tropis dataran rendah, semuanya dalam hamparan yang masih alami sehingga menjadikan kepulauan Karimunjawa sebagai Taman Nasional Laut. Kekayaan flora dan fauna Karimunjawa membuatnya menjadi begitu memesona. Daerah ini memiliki beberapa jenis ekosistem flora, yaitu ekosistem terumbu karang, hutan mangrove (padang lamun), hutan pantai, dan hutan dataran rendah. Di sisi lain, fauna pun bervariasi, seperti rusa dan kera ekor panjang maupun fauna akuatik yang terdiri atas 242 jenis ikan hias dan 133 jenis akuatik. Selain itu, di lokasi ini terdapat pula jenis fauna langka yang berhabitat di pulau Burung dan pulau Geleang, seperti burung Elang Laut dada putih serta dua jenis penyu, yaitu penyu Sisik dan penyu Hijau.

Taman Nasional Karimunjawa merupakan gugusan 27 buah pulau yang memiliki tipe ekosistem hutan hujan dataran rendah, padang lamun, algae, hutan pantai, hutan mangrove, dan terumbu karang. Tumbuhan yang menjadi ciri khas Taman Nasional Karimunjawa yaitu dewodaru (Crystocalyx macrophyla) yang terdapat pada hutan hujan dataran rendah. Kelompok algae yang dapat dijumpai terdiri dari tiga kelompok yaitu algae hijau, algae coklat, dan algae merah. Hutan pantai dan hutan mangrove dicirikan dengan adanya ketapang (Terminalia cattapa), cemara laut (Casuarina equisetifolia), jati pasir (Scaerota frustescens), setigi (Strebus asper), waru laut (Hibiscus tiliaceus), dan bakau hitam (Rhizophora mucronata). Jenis terumbu karang di Taman Nasional Kari- munjawa 
merupakan terumbu karang pantai/ tepi (fringing reef ), terumbu karang penghalang (barrier reef ) dan beberapa taka (patch reef). Kekayaan jenisnya mencapai 51 genus, lebih dari 90 jenis karang keras dan 242 jenis ikan hias. Dua jenis biota yang dilindungi yaitu akar bahar/karang hitam (Antiphates spp.) dan karang merah (Tubipora musica).

Biota laut lainnya yang dilindungi seperti kepala kambing (Cassis cornuta), triton terompet (Charonia tritonis), nautilus berongga (Nautilus pompillius), batu laga (Turbo marmoratus), dan 6 jenis kima. Keanekaragaman satwa darat di taman nasional ini tidak terlalu tinggi dibandingkan dengan satwa perairan. Satwa darat yang umum dijumpai antara lain rusa (Cervus timorensis subspec), kera ekor panjang (Macaca fascicularis karimondjawae); 40 jenis burung seperti pergam hijau (Ducula aenea), elang laut perut putih (Haliaeetus leucogaster), trocokan/merbah cerukcuk (Pycnonotus goiavier), betet (Psittacula alexandri), penyu sisik (Eretmochelys imbricata), penyu hijau (Chelonia mydas), dan ular edhor. Burung elang laut perut putih merupakan satwa yang terancam punah di dunia.

Di sekitar Pulau Kemujan terdapat bangkai kapal Panama INDONOR yang tenggelam pada tahun 1955, dimana pada saat ini menjadi habitat ikan karang dan cocok untuk lokasi penyelaman (wreck diving). Dari gugusan pulau-pulau yang berjumlah 27 buah, lima buah pulau diantaranya telah berpenghuni yaitu Pulau Karimunjawa, Pulau Kemujan, Pulau Parang, Pulau Nyamuk, dan Pulau Genting. Pulau Karimunjawa menjadi pusat kecamatan yang berjarak $\pm 83 \mathrm{~km}$ dari Kota Jepara (pusat pengrajin ukiran kayu yang terkenal di Indonesia). Keindahan panorama alam eko- wisata karimunjawa seperti terumbu karang, rumput laut, dan padang lamun dengan biota laut yang beraneka ragam, hutan mangrove, gunung dan hamparan hutan tropis dataran rendah, semuanya dalam hamparan yang masih alami sehingga menjadikan kepulauan Karimunjawa sebagai Taman Nasional Laut. Kepulauan ini secara administratif merupakan kecamatan dari wilayah ka- bupaten Jepara, yang berlokasi sekitar 45 mil arah barat laut kota Jepara. Luas wilayah teritorial Karimunjawa adalah 107.225 ha, sebagian besar berupa lautan (100.105 ha), luas daratannya sendiri adalah 7.120 ha. Daerah ini beriklim tropis yang dipengaruhi oleh angin laut yang bertiup sepanjang hari dengan suhu rata-rata 26 s.d. 30 derajat Celcius, dengan suhu minimum 22 derajat Celcius dan suhu maksimum 34 derajat Celcius.

Kekayaan flora dan fauna Karimunjawa membuatnya menjadi begitu mem- pesona. Daerah ini memiliki beberapa jenis ekosistem flora, yaitu ekosistem terumbu karang, hutan mangrove (padang lamun), hutan pantai, dan hutan dataran rendah. Di sisi lain, fauna pun bervariasi, seperti rusa dan kera ekor panjang maupun fauna akuatik yang terdiri atas 242 jenis ikan hias dan 133 genera akuatik. Selain itu, di lokasi ini terdapat pula jenis fauna langka yang berhabitat di pulau Burung dan pulau Geleang, seperti burung elang laut dada putih serta dua jenis penyu, yaitu penyu sisik dan penyu hijau.

\section{Legenda Nyamplungan}

Nama Karimun menurut cerita rakyat setempat tidak terlepas dari sosok sunan Nyamplung, yang bernama asli Syech Amir Hasan, putera dari sunan Muria. Sedari kecil, ia hidup dimanja sehingga ketika beranjak dewasa, ia menjadi cenderung nakal. Sunan Muria sudah berusaha mendidik puteranya tersebut agar menjadi lebih baik, tetapi selalu gagal. Akhirnya sunan Muria menitip- kan puteranya kepada sunan Kudus, dengan harapan menjadi lebih baik. Di bawah bimbingan sunan Kudus, Amir Hasan memang menjadi pribadi yang lebih baik dan taat, sehingga ia dikembalikan kepada keluarganya. Tetapi setelah berkumpul kembali dengan keluarganya, perilaku Amir Hasan kembali seperti semula. Sunan Muria merasa prihatin, dan akhirnya memerintahkan puteranya tersebut untuk turun gunung Muria dan mengamalkan ilmu agama di pulau yang nampak ìkremun-kremunî (tidak jelas) bila dilihat dari gunung Muria. Dan sunan Muria pun mengatakan bahwa Amir Hasan tidak boleh kem- bali ke pulau Jawa sebelum tugasnya selesai. Dengan berbekal 2 buah biji Nyamplung untuk ditanam di pulau tujuan, dan mustaka masjid (sampai saat ini masih berada di kompleks makam sunan Nyamplungan), serta ditemani oleh 2 orang abdi, akhirnya Amir Hasan pun 
memulai perjalan- nya. Setelah sampai dan menemukan tempat yang cocok untuk ditinggali, Amir Hasan kemudian menanam 2 buah biji Nyamplung yang dibawanya dari pulau Jawa. Tanaman yang tum- buh dari kedua biji Nyamplung inilah yang sekarang dikenal sebagai pohon Nyamplung, dan lokasinya diberi nama dukuh Nyamplung.

\section{Kepulauan Karimunjawa}

Karimunjawa sejak tahun 2001 memiliki nama resmi Taman Nasional Karimunjawa. Taman ini terdiri atas gugusan 27 buah pulau kecil dengan 5 pulau yang sudah berpenduduk di kepulauan ini dan sisanya ke 22 pulau tidak berpenduduk. Pulau yang sudah berpenduduk yaitu Pulau Genting, Pulau Kemujan, Pulau Karimunjawa, Pulau Nyamuk, dan Pulau Parang. Sebagian besar pulau di sana memiliki pantai dengan pasir putih; antara lain Pulau Menjangan Besar, Menjangan Kecil, Cemara Kecil, dan Tanjung Gelam.

Di Pulau Menjangan Besar terdapat penangkaran ikan hiu. Anda dapat menguji keberanian dengan masuk ke kolam penangkaran dan berenang bersama ikan-ikan hiu ini. Ikan hiu ini sudah dijinakkan dan bersahabat dengan manusia. Pulau Menjangan Kecil pantas dikunjungi karena di perairan sekitar pulau ini terdapat banyak ikan kecil berwarna-warni yang cantik. Pulau ini memiliki pantai dan dasar laut yang indah dengan air yang jernih. Pulau ini cocok bagi Anda yang ingin mencoba snorkeling.

Pada pulau Cemara Kecil dan Besar ini terdapat banyak pohon cemara yang mungkin menjadi dasar nama kedua pulau ini. Hal unik lainnya adalah adanya daratan pantai dengan pasir putihnya yang menjorok ke laut. Pulau cemara ini merupakan area wisata pantai pasir putih yang sangat indah. Pulau Tanjung Gelam merupakan pulau yang indah dengan hamparan pasir putih dan air laut yang berwarna hijau kebiruan.

\section{Penduduk}

Penduduk kepulauan Karimunjawa terdiri atas beberapa suku yang memiliki identitas tersendiri seperti bentuk rumah adat yang khas. Suku-suku yang mendiami kepulauan Karimunjawa adalah suku Jawa, Bugis Makasar, dan Madura. Masyarakat Jawa banyak tinggal di dukuh Karimun, dukuh Legon Lele, dukuh Nyamplungan, dan dukuh Mrican. Sebagian besar mata pencaharian masyarakat Jawa adalah bertani dan membuat industri rumah tangga, seperti batu bata merah dan minyak kelapa. Masyarakat Bugis Makasar sebagian besar bertempat tinggal di pulau Kemujan, dukuh Batu Lawang, dukuh Legon Gede, dan dukuh Tlogo. Masyarakat Bugis terkenal sebagai pelaut yang ulung, oleh karena itu sebagian besar masyarakatnya berprofesi sebagai nelayan. Selain itu, tenun sarung Bugis juga merupakan kekhasan yang lain dari masyarakat Bugis. Masyarakat Madura pun sebagian besar berprofesi sebagai nelayan dan memiliki kemampuan membuat ikan kering industri rumahan.

\section{Daya Tarik Wisata}

Karimunjawa menawarkan daya tarik wisata alam yang indah, yaitu wisata bahari dan wisata petualangan alam. Selain alam yang indah, penduduk Karimunjawa yang multietnis membuat kawasan ini pun menarik untuk disimak berbagai keunikan budaya dan tradisinya. Wisata bahari menawarkan berbagai kegiatan wisata dan olahraga yang berhubungan dengan alam kepulauan Karimunjawa. Beberapa aktivitas wisata sebagai berikut.

Kegiatan menyelam dapat dilakukan di sebelah utara dan barat pulau Karimunjawa, sebelah timur pulau Menjangan Besar, sekitar pulau Menjangan Kecil, sebelah selatan dan barat pulau Geleang, sebelah barat pulau Bengkoang, sebelah barat pulau parang, sebelah timur pulau Kembar, sekitar pulau Katang, sebelah utara dan timur pulau Krakal Kecil, dan sebelah barat pulau Kumbang. 
Aktivitas snorkeling dapat dilakukan di pulau Menjangan Besar dan Menjangan Kecil, sebelah barat pulau Bengkoang, sekitar pulau Kembar, sebelah utara dan timur pulau Krakal Kecil. Aktivitas memancing dapat dilakukan di sekitar pulau Menjangan Besar dan Kecil, pulau Menyawakan, pulau Tengah, pulau Kemujan, pulau Parang, sekitar pulau Kembar, dan sebelah barat pulau Bengkoang.

Lokasi berenang yang dapat dipakai untuk melakukan aktivitas ini antara lain di sebelah timur dan selatan pulau Karimunjawa, bagian selatan dan barat pulau Menjangan Kecil, bagian barat pulau Tengah, sekitar pulau Parang, pulau Kembar, dan pulau Kumbang.

Hampir seluruh pantai di kepulauan Karimunjawa berpasir putih dengan garis pantai yang cukup panjang. Kondisi ini menyebabkan kawasan pantai menjadi kawasan yang cocok untuk melakukan kegiatan berjemur (mandi matahari), bermain pasir, dan menyaksikan keinda- han pemandangan matahari terbit atau matahari terbenam. Bagi yang tidak dapat berenang dan menyelam, tersedia kapal yang dilengkapi dengan kaca pada bagian bawahnya (glass bottom boat) untuk menyaksikan keindahan bawah laut Karimunjawa.

Di pulau Menjangan Besar terdapat area yang memiliki fasilitas akuarium air laut. Di sini, kita dapat menikmati keindahan ikan hias dan kehidupan ikan hiu serta ikan-ikan lainnya dengan nuansa khas yang tidak dapat ditemui di tempat lain.

Selain alamnya, faktor penduduk dan tradisinya membuat kepulauan Kari- munjawa memiliki daya tarik wisata budaya dan ziarah. Berbagai atraksi budaya terdapat di kawasan ini, sep- erti reog (kuda lumping), pencak silat, rebana, dan gamelan Jawa. Ada juga atraksi-atraksi yang dilakukan secara ru- tin oleh masyarakat setempat, misalnya pelepasan penyu, upacara pelepasan perahu, dan khoul sunan Nyamplungan (peringatan satu Suro). Legenda Nyamplungan membuat kawasan ini menarik untuk dikunjungi oleh para peziarah yang ingin mendatangi makam sunan Nyamplungan dan peninggalan-peninggalannya.

Berbagai macam barang kerajinan yang sebagian besar terbuat dari kayu-kayu langka, seperti kayu Setigi, kayu Dewa- daru, dan kayu Kalimasada merupakan keunikan tersendiri dari kepualauan Karimunjawa. Hasil-hasil kerajinan yang lain berupa tongkat, keris, dan tasbih. Selain hasil kerajinan, di kepulauan ini juga terdapat barang-barang cinderamata lainnya berupa hasil industri rumah tangga, seperti kaus, topi, ikan teri, ikan asin, jenang, makanan olahan dari rumput laut, dan minyak kelapa.

Barang-barang kerajinan ini dapat dengan mudah diperoleh di toko-toko penjual barangbarang cinderamata yang berada di pusat kota Karimunjawa. Untuk kerajinan kayu, ada beberapa lokasi sebagai pusat kerajinan kayu untuk tempat pemesanan, sebagai berikut: Pusat Kerajinan Al Badri, desa Legon Cikmas Labiki, Jalan Kapuran, pulau Karimunjawa (lihat Gambar 1).

\section{Transportasi ke Karimunjawa}

Untuk menuju Karimunjawa, dapat menggunakan beberapa alternatif pilihan berikut: Kapal Cepat dari Semarang; dari Semarang, Anda dapat pergi ke Karimunjawa melalui Pelabuhan Tanjung Emas dengan menggunakan kapal cepat. Perjalanan dari Semarang ke Karimunjawa sekitar 4 jam hingga 6 jam jika cuaca buruk.

Kapal dari Jepara; jika Anda memilih pergi ke Karimunjawa dari Jepara, Anda dapat melalui Pelabuhan Kartini. Anda bisa memilih menggunakan kapal cepat, atau juga menggunakan kapal yang lambat dan murah dari Jepara. Perjalanan dari Jepara ke Karimunjawa sekitar 2,5 hingga 3 jam. 

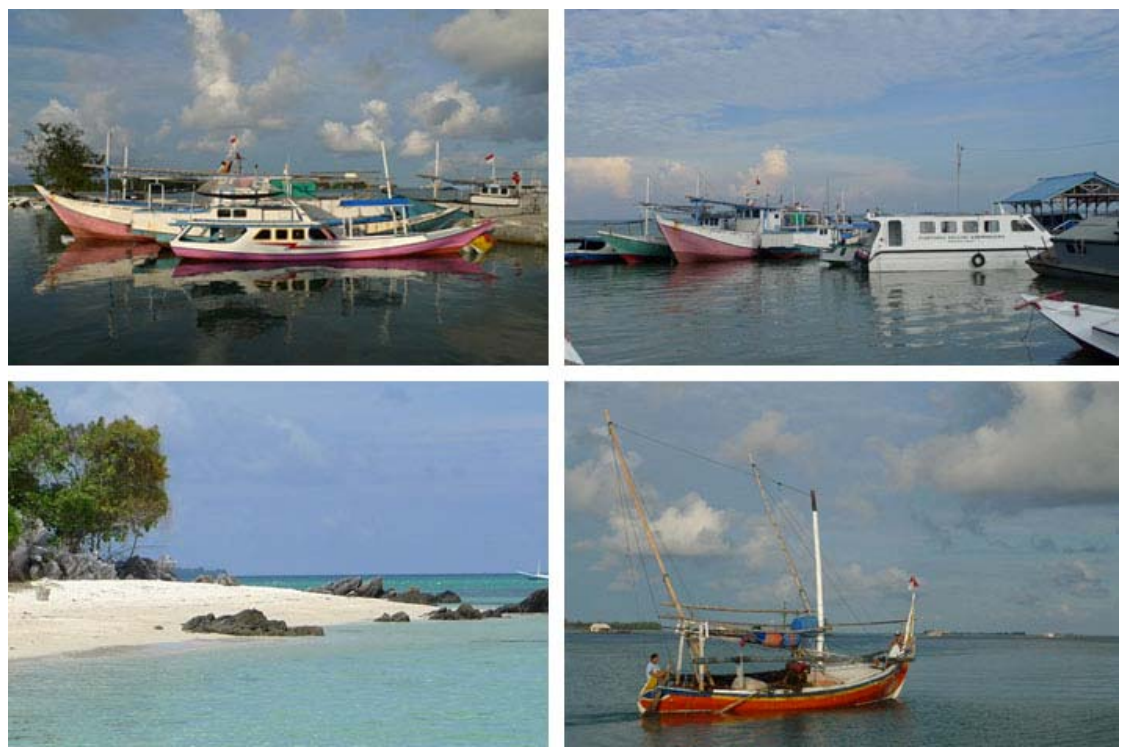

Gambar 1 Beberapa Sudut Wilayah Air di Karimunjawa

Pesawat; selain itu, bagi Anda yang memiliki cukup dana, ada pesawat kecil di Bandara Ahmad Yani Semarang dapat disewa menuju Bandar Udara Dewa Daru di Pulau Kemujan (salah satu pulau di Karimunjawa). Dengan pesawat, Anda dapat melihat keindahan Karimunjawa dari atas sebelum mendarat di lapangan terbang yang ada di Karimunjawa. Perjalanan dengan pesawat menempuh waktu sekitar 30 menit.

Menikmati keindahan pulau ini dan merasakan ketenangannya akan menjadi pengalaman yang menyenangkan. Dianjurkan untuk mengunjungi pulau ini pada bulan Maret sampai Oktober, pada saat itu cuaca sedang bersahabat sehingga Anda dapat leluasa menjelajah dan menikmati kepulauan Karimunjawa. Nikmati pesona keindahan alam di Karimunjawa.

\section{Akomodasi di Karimunjawa}

Selain menikmati keindahan laut dan pantainya, Anda dapat mengunjungi pasar tradisional atau mengunjungi para pelayan yang berhasil mendapat ikan di pasar ikan. Untuk tempat penginapan, ada beberapa pilihan tempat yang bisa Anda tentukan. Anda dapat menginap di beberapa resort mewah yang ada di pulau-pulau kecil atau juga hotel-hotel dengan tarif yang lebih murah. Beberapa penduduk setempat juga menyewakan rumahnya dengan tarif yang lebih murah lagi. Atau Anda bisa mencoba suasana berbeda dengan menginap di Wisma Apung, yaitu tempat penginapan yang ada di atas air tidak jauh dari pantai.

\section{Sarana Telekomunikasi}

Kepulauan Karimunjawa telah dilengkapi jaringan telekomunikasi yang didukung oleh PT Telkom. Dengan adanya fasilitas ini, berkomunikasi lewat telepon baik nasional maupun internasional dapat dilakukan. Untuk jaringan telepon seluler, saat ini telah tersedia jaringan dari Telkomsel, dan dalam waktu dekat akan masuk operator seluler lainnya.

\section{Sarana Kesehatan}

Kawasan Karimunjawa juga telah dilengkapi oleh banyak pos-pos kesehatan yang didukung oleh tenaga medis yang memadai. Dengan adanya pos-pos kesehatan ini, diharapkan fasilitas pertolongan pertama terhadap korban musibah dapat cepat dilakukan. 


\section{METODE PENELITIAN}

Penulisan artikel ini menggunakan metode analisis formal. Penulis mengumpulkan bahanbahan yang mendukung perancangan visual, berupa data mengenai wilayah Karimunjawa, baik verbal maupun visual, dan eksplorasi kreatif dari penulis sendiri. Penulis mengumpulkan referensi mengenai desain desain identitas visual (khususnya yang berkaitan dengan destination branding) pada bukubuku teks dan website. Penulis membuat analisis peran kreativitas dalam mendukung efektivitas desain identitas visual wilayah Karimunjawa. Setelah melalui tahap pengumpulan data, mengumpulkan referensi, memetakan konsep kreatifnya, merancang alternatif desain dalam bentuk sketsa, maka tahap berikutnya adalah merancang alternatif desain identitas visual beserta contohcontoh aplikasinya.

\section{HASIL DAN PEMBAHASAN}

Dalam perkembangan zaman yang semakin maju, semakin tinggi pula jumlah penduduk dan aktivitasnya. Dengan aktivitas penduduk yang tinggi diperlukan sistem informasi yang baik dan terpadu. Sistem informasi yang dimaksud salah satunya adalah wayfinding seringkali disebut sistem rambu atau bisa juga disebut tanda atau penunjuk arah. Karena sign system banyak membantu masyarakat di dunia, dan bisa digunakan sebagai pengatur mobilitas yang semakin banyak. Di tengah padatnya arus pergerakan atau perpindahan dari satu lokasi ke lokasi yang tinggi pada saat ini, maka sebuah sistem informasi yang dirancang dengan baik akan mampu menjawab kebutuhan sistem informasi. Latar belakang masyarakat yang berbeda-beda, seperti pendidikan, ekonomi, bahkan pekerjaan yang beragam adalah hal yang perlu diperhatikan dalam membuat sistem informasi terutama menyangkut jasa layanan dengan jumlah khalayak pengguna yang banyak. Masalah seperti mengatur arus pengunjung yang masuk dan keluar, pelayanan jasa, informasi bahkan sampai penunjuk arah menuju kamar kecil adalah bagian dari sebuah sistem informasi yang memerlukan perancangan khusus.

Bisa dikatakan hampir di setiap tempat dengan mobilitas yang tinggi diperlukan sistem informasi yang tepat dan akurat. Taman Nasional Karimunjawa (TN Karimunjawa) sebagai salah satu tempat wisata di wilayah Jepara yang memerlukan sistem informasi untuk membantu aktivitas pengunjungnya di dalam TN Karimunjawa, sebagai contoh penunjuk arah untuk wisata laut maupun tempat penangkaran hewan lindung atau seperti empat wisata camping ground, tracking, hiking, dst. Selain sign system yang di perlukan untuk mengatur aktivitas pengunjung di tempat umum, dengan mobilitas yang cukup tinggi, juga diperlukan sign informasi penunjuk lokasi/tempat beristirahat bagi masyarakat pengunjung. Di TN Karimunjawa banyak didirikan tempat beristirahat seperti hotel, resort, dan lain-lainnya sebagai salah satu fasilitas yang disediakan untuk pengunjung yang berasal dari luar kota maupun wilayah dari dalam kota. Demi menjaga keberadaan TN Karimunjawa, maka perlu di adakan pembenahan-pembenahan yang nantinya menjadi salah satu daya tarik pengunjung. Dan penandaan fasilitas-fasilitas baru yang belum ada sistem rambunya. Adapun masalah-masalah yang ada di TN Karimunjawa, antara lain: luasnya area TN Karimunjawa sehingga diperlukan penanganan secara khusus dalam sistem penandaan. Sistem keberadaan zonasi yang belum terbagi sesuai dengan karakter wilayah. Sistem rambu yang harus dibenahi dan disesuaikan dengan pembagian kelompok zonasi, dan dibuat menarik dari segi visual. Kurangnya fasilitas-fasilitas pendukung yang menarik pengunjung.

Pembahasan dibatasi hanya pada proyek identifikasi hingga perancangan identitas visual yang meliputi: desain logo kawasan, tipografi, warna, pictogram dan implementasi wayfinding / sign system, yang terkait pada pembenahan sistem penandaan / rambu TN Karimunjawa. 
Sistem rambu atau sistem penanda dan informasi merupakan keharusan bagi keberadaan tempat-tempat rekreasi seperti TM Karimunjawa. Dari sistem rambu ini para pengguna sarana rekreasi memperoleh informasi yang dibutuhkan dengan cepat dan jelas. Informasi seperti Peta Lokasi, Zona Wisata hingga fasilitas publik adalah bagian dari informasi sebuah wilayah taman rekreasi. Sistem penanda dan informasi adalah satu kesatuan yang tak terpisahkan dari sarana rekreasi ini. Dengan sistem rambu atau sistem penanda yang di kemas visualnya secara menarik selain mampu memberikan informasi juga dapat mem- buat nilai tambah pada taman rekreasi TM Karimunjawa.

Proses perancangan dimulai dari menganalisis permasalahan yang timbul, kemudian dilanjutkan dengan proses pengumpulan data atau inventarisasi data. Data-data yang diperoleh kemudian diidentifikasi, dianalisis, kemudian menyusun program perencanaan media serta pendekatan kreatifnya degan menggunakan metode sintesis.

Proyek perancangan identitas visual Karimunjawa ini meliputi: desain Logo Landmark Karimunjawa, desain Tipografi, desain Piktogram, Sign System. Proses perancangan dalam program penandaan wilayah Karimunjawa ini dimulai dengan pemikiran yang terstruktur dan strategis, yang terdiri dari: menemukan fakta-fakta kunci mengenai Karimunjawa, mencari pembeda (differentiation); menentukan Positioning; menentukan kesan visual yang akan dicapai (design look, tone \& manner) dalam implementasi bentuk, warna dan huruf; mencari referensi visual dalam bentuk foto, gambar, video, ilustrasi, dll; membuat alternatif sketsa; membuat bentuk vektor komputer dari sketsa terpilih; implementasi desain.

\section{Fakta Kunci Tentang Karimunjawa}

Kepulauan Karimunjawa secara administratif merupakan kecamatan dari wilayah kabupaten Jepara, yang berlokasi sekitar 45 mil arah barat laut kota Jepara. Kekayaan flora dan fauna Karimunjawa membuatnya menjadi begitu memesona. Pantainya yang masih 'perawan' dengan kondisi air pantai yang jernih membuat Karimunjawa menjadi Taman Laut Nasional. Hutan Mangrove yang masih terjaga utuh dan sangat luas menjadikan kepulauan Karimunjawa sebagai destinasi wisata alam dan bahari yang sangat menarik.

Karimunjawa adalah surga wisata laut di Pulau Jawa. Kehidupan bawah laut dengan berbagai biotanya yang luar biasa, pantai-pantai berpasir putih nan indah, pulau-pulau kecil mempesona, serta masyarakat yang ramah dan bersahaja menjadi daya pikat taman laut nasional ini. Kepulauan Karimunjawa yang terletak $230 \mathrm{~km}$ utara Yogyakarta terdiri atas gugusan 27 pulau, 22 di antaranya adalah pulau tak berpenghuni cantik dengan pantai berpasir putih yang menawan. Taman Laut Nasional Karimunjawa adalah salah satu Taman Laut Nasional di Indonesia dengan luas total 111.625 ha. Dari luas itu, 98,6\% merupakan wilayah perairan sementara 1,4\% wilayah daratan.

Karimunjawa memiliki keanekaragaman hayati yang sangat tinggi, antara lain 69 marga karang keras, 353 spesies ikan karang dan 300 hektar hutan mangrove. Kepulauan Karimunjawa adalah salah satu dari sedikit tempat untuk menemukan Penyu Sisik (Eretmochelys imbricata), Penyu Hijau (Chelonia Mydas) dan Elang Laut Perut Putih (Haliaetus leucogaster) yang merupakan hewan yang terancam punah. Terdapat kolam penangkaran ikan hiu di Pulau Tengah dan Pulau Menjangan Besar yang juga menjadi salah satu daya tarik wisata. Penggemar kegiatan yang memacu adrenaline bisa mencoba kesempatan untuk berenang bersama predator berbahaya ini.

Banyak terdapat gosong di perairan Karimunjawa, yaitu daratan pasir yang menyembul di tengah laut atau di tepi pulau yang nampak pada pagi hari dan kemudian menghilang ketika air laut pasang. Fenomena global warming menyebabkan peningkatan suhu air laut hingga 1 derajat Celcius per tahun, mengakibatkan terjadinya coral bleaching dan matinya terumbu karang, termasuk terumbu karang di perairan Karimunjawa. Penduduk Karimunjawa mempergunakan generator sebagai pembangkit tenaga listrik. Keterbatasan sumber tenaga ini menyebabkan listrik hanya menyala dari jam 6 sore hingga jam 6 pagi. 


\section{Tujuan Perancangan}

Menumbuhkan kesadaran akan pentingnya suatu sistem informasi yang baik dan terpadu dan memberikan dampak yang baik. Secara psikologis para pengunjung merasa bahwa wilayah yang dikunjungi telah memiliki identitas visual dan ditata serta dikelola dengan baik, dan akan memengaruhi segi keamanan maupun kenyamanan dalam berwisata.

Tentunya Sistem informasi wayfinding ini akan memberikan solusi ketika para pengunjung berada dalam suatu wilayah wisata yang sangat luas yang terdiri dari 27 pulau, dengan aneka tawaran wisata. Dengan zonasi para pengunjung akan dimudahkan dalam menemukan lokasi tujuan yang hendak dicapai.

Sasaran komunikasi TN Karimunjawa utama adalah pengunjung atau wisatawan domestik. Hal ini sesuai dengan data di lapangan yang menunjukkan bagian terbesar dari pengunjung Karimunjawa adalah wisatawan lokal yang berasal wilayah Jawa Tengah, Jawa Timur, Jakarta, dan sebagian dari luar pulau Jawa.

Sementara itu, wisatawan asing, meskipun ada namun masih dalam kisaran jumlah kecil. Pada umumnya para pengunjung datang ke Karimunjawa dengan banyak tujuan selain untuk bersenangsenang, misalnya melepas kepenatan, petualangan, pengetahuan atau riset, dan lain-lain. Pengunjung Taman Nasional Karimunjawa terbagi secara demografis dan psikografis. Secara demografis, pengunjung Karimunjawa adalah Pria dan Wanita dewasa, berumur antara 17-35 th; masih kuliah atau sudah bekerja; pendidikan SMU, Sarjana; SES C+, B, B+; tinggal bersama orang tua, bila sudah berkeluarga, dengan 1 -2 anak balita; bekerja atau wiraswasta; memilki kendaraan pribadi. Sedangkan secara psikografis: fun seeker (suka mencari kegembiraan); adventurer (suka pengalaman berpetualang); communities (suka hidup berkomunitas) ceria, optimis, kreatif, memiliki sifat bertualang yang besar, suka pergi berlibur; memiliki kegiatan nonformal, hobi tertentu, misalnya fotografi, dll; suka berdiskusi dan aktif di jejaring sosial; berpikir kreatif dan suka tantangan; aktif dalam kelompok; antusias terhadap hal-hal baru; menyukai kehidupan alam; suka bersahabat (lihat Gambar 2).

\section{The Big Idea}

Perancangan visual Penandaan wilayah Karimunjawa ini didasarkan pada konsep besar atau the big idea yang sekaligus menjadi payung dalam pengembangan desain selanjutnya. The big idea diperoleh dari brainstorming dan berdasarkan data-data, tujuan, serta profil sasaran komunikasi “Beautifully Wonderful” (lihat Gambar 3).

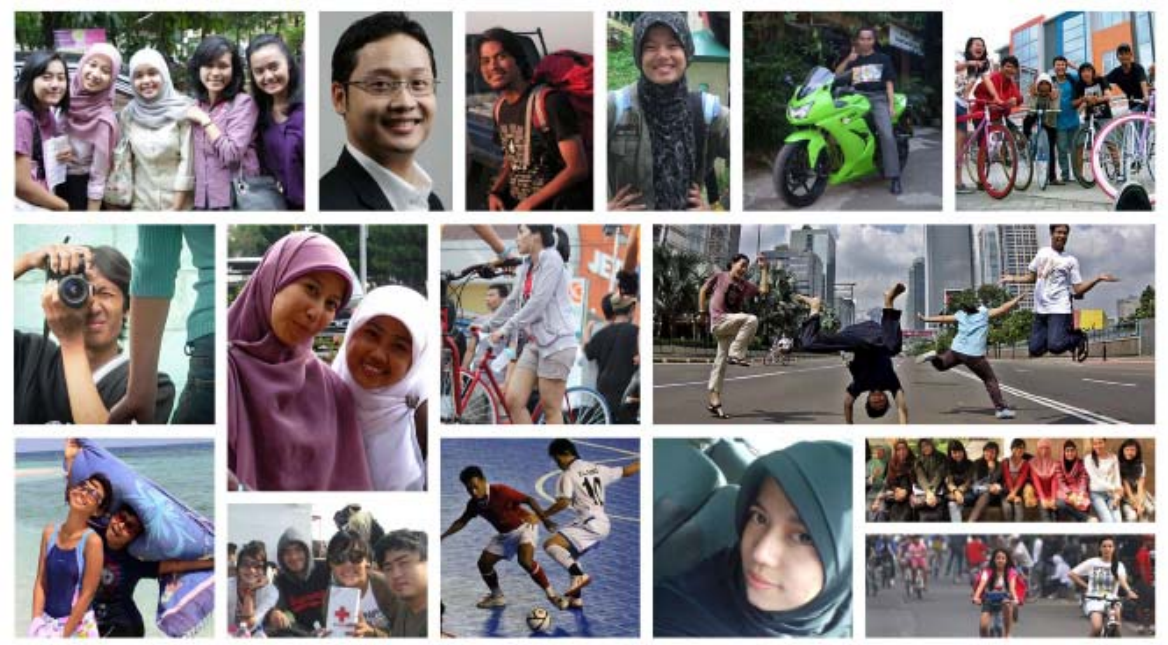

Gambar 2 Profil Sasaran Komunikasi 


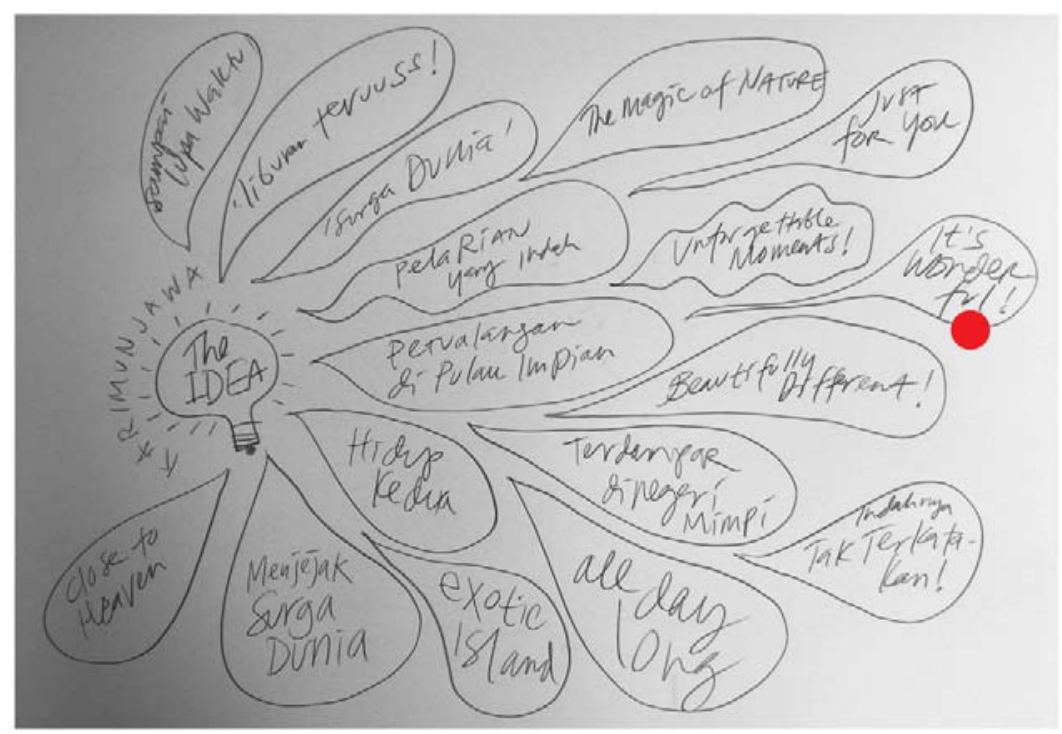

Gambar 3 Proses Brainstorming Eksplorasi Gagasan Awal

\section{Strategi Visual}

Sistem informasi Taman Nasional Karimunjawa memvisualisasikan keunikan kawasan dengan memberikan sentuhan ciri khas wisata kelautan serta aktivitas masyarakatnya, diwujudkan dalam bahasa visual yang komunikatif dan sederhana, dilakukan dengan pendekatan piktogram. Kesan visual (Tone \& Manner) yang ingin ditampilkan adalah: "Fun”, desain terlihat menyenangkan, membuat suasana gembira dan riang; "Natural”, mengembangkan bentuk dan warna yang diinspirasi dari alam, khususnya alam Karimunjawa (misalnya: laut, flora, fauna, dll); dan "Leisure", desain berkesan santai, sederhana, dan nyaman, tidak kaku dan tidak membosankan.

Proses adalah hal yang menjadi dasar dalam perancangan desain penandaan wilayah Karimunjawa ini. Dalam hal ini, pengembangan kreatif hingga visualisasi desain digambarkan melalui skema di bawah ini: Konsep Kreatif (verbal) $\rightarrow$ Referensi Visual $\rightarrow$ Alternatif Sketsa $\rightarrow$ Digitalisasi/ Vektor $\rightarrow$ Implementasi Desain. Perhatikan gambar skema proses visualisasi berikut.

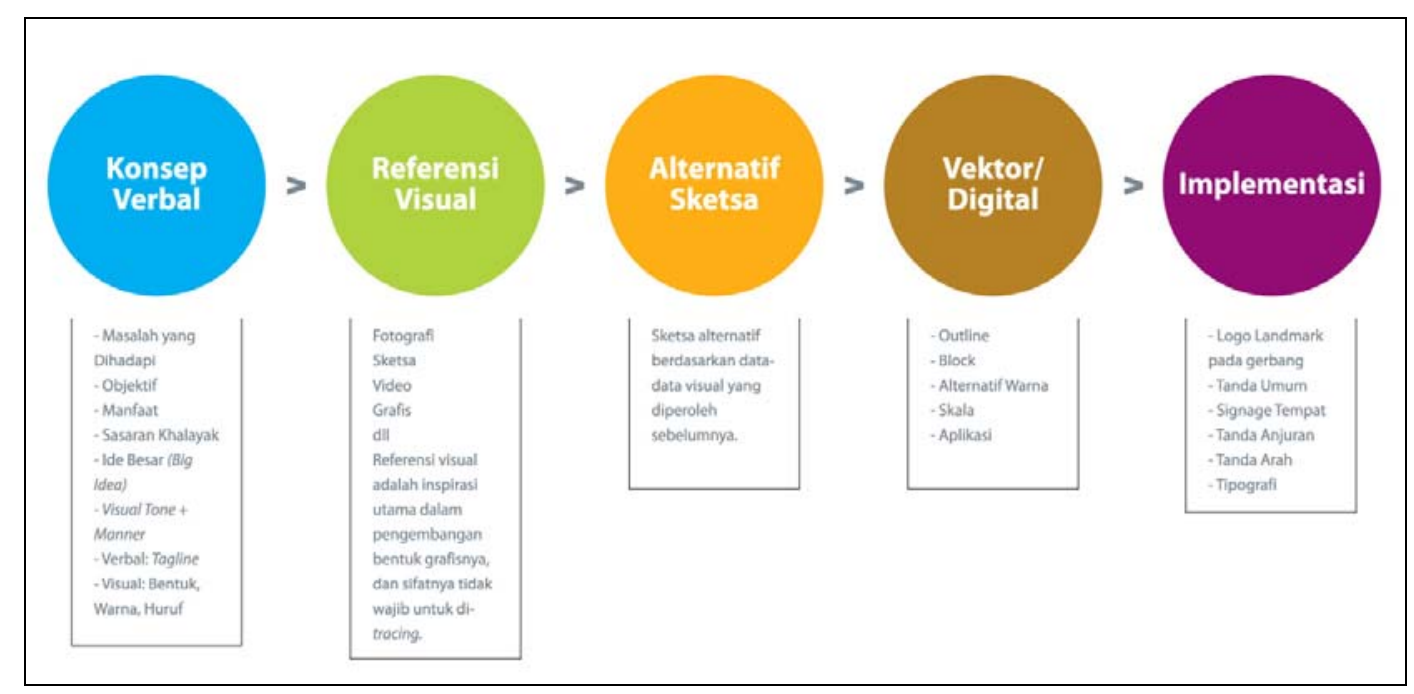

Gambar 4 Skema Proses Visualisasi 


\section{Konsep Perancangan}

Bagian awal dalam menerjemahkan konsep menjadi implementasi visual adalah merancang logo kawasan Karimunjawa. Logo adalah representasi visual dan mewakili aspek-aspek citra, nilai, sistem dan komunikasi dari sebuah institusi. Dewasa ini, berkembang wacana brand dan branding yang merupakan jiwa dari sebuah institusi. Brand adalah representasi keseluruhan dari sebuah institusi, organisasi atau individu. Brand adalah representasi dari semangat, nilai-nilai, jiwa, dan mimpi dari suatu entitas. Brand adalah intangible asset. Sedangkan logo sering disebut sebagai gerbang utama dari sebuah brand, karena logo paling mudah dilihat, disentuh, dan dirasakan oleh audiensi. Brand yang baik harus mampu mendelegasikan fungsinya kepada medium-medium komunikasinya yang terintegrasi. (Lihat Gambar 5).

Karimunjawa sebagai sebuah destinasi brand dinyatakan sebagai daerah tujuan wisata yang eksotis, asli-alami, indah, menyenangkan dan penuh petualangan seru, dan dinyatakan sebagai "Beautifully Different". Sebelum proses perancangan logo dilakukan, kita mengenali terlebih dahulu beberapa kriteria logo yang baik dilihat dari fungsi dan tujuannya. Logo yang baik mengandung beberapa kriteria sebagai berikut.

Logo yang baik adalah logo yang sederhana (simple). Kesederhanaan membuat logo mudah diingat dan fleksibel ketika diterapkan kedalam berbagai media visual, contoh: logo NIKE. Logo yang baik juga harus unik dan mudah dibedakan dengan logo lain (khususnya logo dari pesaing), contoh: logo UNILEVER.

Selain itu, logo yang mudah diingat akan mendukung perusahaan tetap dalam posisi teratas dalam ingatan konsumen. Secara tidak langsung ini akan meningkatkan penjualan dan omset dari perusahaan, contoh: logo WWF. Logo yang bertahan lama tentu akan sangat menguntungkan perusahaan. Perubahan logo juga dapat membingungkan konsumen dan bahkan bukan tidak mungkin akan kehilangan banyak pelanggan, contoh: logo COCA COLA.

Suatu logo harus bersifat fleksibel karena akan digunakan dalam berbagai media visual seperti stempel, akrilik, faktur, dll. Oleh karena itu, sebuah logo yang baik harus bisa ditempatkan di berbagai kondisi dan tetap tidak kehilangan esensinya. Sebagai tambahan, logo juga harus memiliki kesesuaian dengan produk yang ditawarkan. Logo harus mampu menggambarkan apa yang ditawarkan oleh perusahaan.

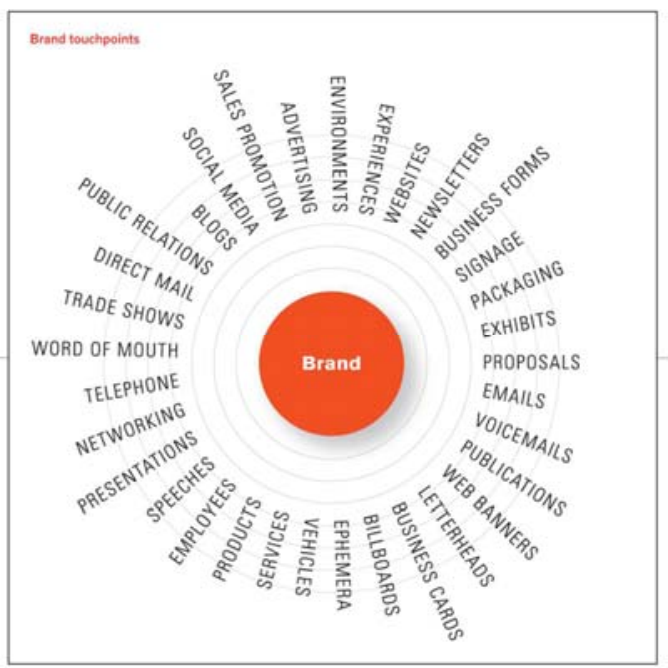

Gambar 5 Bagan Brand Touchpoint (Alina Wheler - Designing Brand Identity) 
Sedangkan menurut Surianto Rustan, S.Sn dalam bukunya “Mendesain Logo”, sebuah logo yang baik harus memiliki kriteria berikut.

\section{Unik}

Keunikan yang harus diperhatikan dari sebuah logo di antaranya: bentuknya memiliki ciri khas tersendiri, memiliki cukup perbedaan dengan logo lain, bentuknya dapat menarik perhatian penglihat, bentuknya tidak membosankan atau ketinggalan jaman.

\section{Simpel}

Logo dapat dikatakan simpel jika mudah ditangkap mata dan dikenali bentuknya; mudah diingat bentuknya; mudah dibaca; memiliki warna yang mudah diingat.

\section{Fleksibel}

Logo dapat dikatakan fleksibel jika memiliki berbagai versi bentuk, sehingga bila diterapkan sesuai dengan kondisi media dan bahan apapun, missal: versi vertikal untuk umbul-umbul, versi horizontal untuk spanduk, versi stempel, bahan kaos, plastik, gelas, kayu, di kendaraan, di billboard, dan lain-lain; mudah dikembangkan sesuai karakteristik media tertentu, misalnya: web, animasi, TV, 3D dan lain sebagainya; mudah dibongkar pasang tanpa kehilangan jati dirinya, baik untuk keperluan estetis maupun fungsional; memiliki berbagai versi warna, sehingga dalam kondisi background dan media apapun logo dapat terlihat jelas; memiliki versi ukuran besar dan kecil, sehingga logo tetap terlihat jelas dalam kondisi media dengan berbagai ukuran ruang. (2009: 42-43)

Visualisasi logo kawasan Karimunjawa dikembangkan berdasarkan aspek KEUNIKAN (unik dan khas dalam bentuk), KESEDERHANAAN (agar dimungkinkan dalam aplikasinya yang beragam), FLEKSIBEL, dan KESESUAIAN (logo menggambarkan objek wisata Karimunjawa baik secara fisik maupun sifat-sifatnya).

Berikut ini adalah proses perancangan logo Karimunjawa: memilih typeface yang sesuai dengan karakter; membuat alternatif sketsa logotype; membuat bentuk vektor komputer dari sket terpilih; mengembangkan alternatif desain dari bentuk vektor pertama; aplikasi warna, skala, dan efek khusus logo; mengembangkan tipografi (alfabet) sebagai bagian dari pengembangan karakter desain; membuat aplikasi logo standar (stationary set).

\section{SIMPULAN}

Artikel ini dibagi menjadi 2 bagian karena terlalu panjang, dimana bagian pertama dimulai dari data awal tentang Karimunjawa, proses pengembangan konsep kreatif, dan visualisasi logo Karimunjawa. Namun, secara umum simpulan dari pembahasan studi kasus perancangan identitas visual wilayah Karimunjawa diuraikan di bagian penutup ini.

Identitas visual suatu wilayah sebaiknya mengacu pada konsep dan strategi destination branding yang kuat dan khas. Identitas visual yang baik adalah layaknya sebuah bangunan yang utuh, seluruh bagian menjadi penting, mulai dari fondasi hingga peran ujung tombaknya. Dengan kata lain, identitas visual bukanlah satu-satunya cara mengomunikasikan sebuah brand wilayah sebagai tujuan wisata, namun harus secara bersama-sama, terintegrasi dalam sebuah konsep dan implementasi yang menyeluruh, efektif dan relevan. Identitas visual dalam wujud desain logo hanyalah rupa, citra secara 
keseluruhan tidak hanya menjadi tanggung jawab desain logo. Implementasi konsep brand berupa visual, verbal, dan mindset dari manusianya, dan harus digerakkan secara bersama-sama.

Pengembangan desain yang baik, harus bertumpu, mengacu dan menunjukkan kekuatan, keunikan dan kekhasan unsur dan nilai-nilai lokalitas. Nilai-nilai lokal yang dimaksud adalah segala hal yang bersifat kekayaan budaya, manusia, seni, flora, fauna, bangunan, artefak, lanskap, keunikan geografis, bahasa, tradisi, peninggalan sejarah, hingga pemikiran dan kearifan masyarakatnya. Peran dan kejelian seorang desainer sangat penting dalam mengemas, merangkum dan mengeksplorasi kekayaan lokal tersebut. Desainer mengekplorasi nilai-nilai yang ada dan mengembangkannya sesuai dengan strategi dan konsep branding yang sudah disusun.

Implementasi desain sangat berpengaruh pada efektivitas komunikasi sebuah brand. Maka, perlu dicermati pemilihan media yang sesuai dan efektif menjangkau sasaran komunikasinya. Desain yang baik, desain yang bagus dan artistik tidak akan pernah berhasil berkomunikasi dengan audiennya, bila tidak memperhatikan integrasi dalam implementasi media komunikasinya. Identitas visual pada hakekatnya adalah wajah, hati, pikiran dan aktivitas yang harus selaras menyampaikan pesan dan gagasan.

\section{DAFTAR PUSTAKA}

Abdullah, R., \& Hubner, R. (2006). Pictograms, Icons \& Signs: A Guide to Information Graphics. London: Thames \& Hudson.

Ambrose, G., \& Harris, P. (2005). Layout. Lausanne, Switzerland: AVA Publishing SA.

Ardya W., Okky. (2008). Environmnetal Graphic Design. Majalah Concept, vol. 04 Edisi 23. Jakarta.

Gibson, D. (2009), The Wayfinding Handbook: Information Design for Public Place. New York: Princeton Architectural Press.

Jenn \& O’Gradyini, K. V. (2008), The Information Design Handbook. Switzerland: Rotovision.

Landa, R. (2006). Graphic Design Solutions. New York: Thomson Delmar Learning.

Samara, T. (2007). Design Elements - A Graphic Style Manual. Beverly: Rockport.

Sihombing, D. (2001). Tipografi dalam Desain Grafis. Jakarta: Gramedia Pustaka Utama.

Tinarbuko, Sumbo. (2009). Semiotika Komunikasi Visual (Edisi Revisi). Yogyakarta: Jalasutera. 